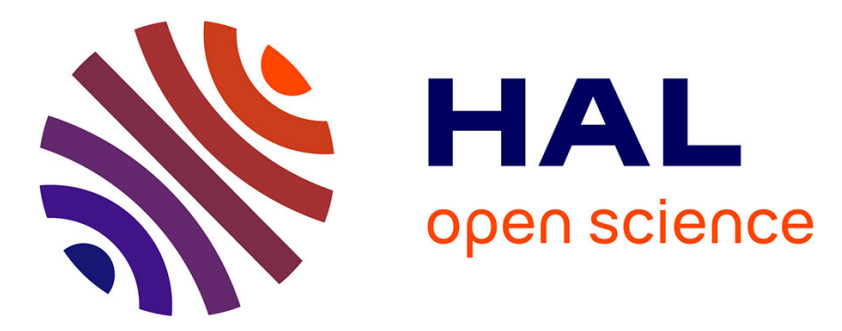

\title{
Theoretical insights into multibandgap hybrid perovskites for photovoltaic applications
}

Jacky Even, Laurent Pedesseau, Claudine Katan

\section{To cite this version:}

Jacky Even, Laurent Pedesseau, Claudine Katan. Theoretical insights into multibandgap hybrid perovskites for photovoltaic applications. SPIE Photonics Europe, Apr 2014, Bruxelles, Belgium. pp.91400Y, 10.1117/12.2052375 . hal-01004488

\section{HAL Id: hal-01004488 \\ https://hal.science/hal-01004488}

Submitted on 11 Jun 2014

HAL is a multi-disciplinary open access archive for the deposit and dissemination of scientific research documents, whether they are published or not. The documents may come from teaching and research institutions in France or abroad, or from public or private research centers.
L'archive ouverte pluridisciplinaire HAL, est destinée au dépôt et à la diffusion de documents scientifiques de niveau recherche, publiés ou non, émanant des établissements d'enseignement et de recherche français ou étrangers, des laboratoires publics ou privés. 


\title{
Theoretical insights into multibandgap hybrid perovskites for photovoltaic applications
}

\author{
J. Even ${ }^{* a}$, L. Pedesseau ${ }^{\mathrm{a}}$, and C. Katan ${ }^{\mathrm{b}}$ \\ ${ }^{\mathrm{a} U n i v e r s i t e ́ ~ E u r o p e ́ e n n e ~ d e ~ B r e t a g n e, ~ I N S A-F O T O N-U M R ~ 6082, ~} 35708$ Rennes, France; ${ }^{\mathrm{b}} \mathrm{CNRS}$, \\ Institut des Sciences Chimiques de Rennes, UMR 6226, 35042 Rennes, France
}

\begin{abstract}
Following pioneering works, the 3D hybrid lead-halide perovskites $\mathrm{CH}_{3} \mathrm{NH}_{3} \mathrm{PbX}_{3}(\mathrm{X}=\mathrm{Cl}, \mathrm{Br}, \mathrm{I})$ have recently been shown to drastically improve the efficiency of Dye Sensitized Solar Cells (DSSC). It is predicted to open "a new era and a new avenue of research and development for low-cost solar cells ... likely to push the absolute power conversion efficiency toward that of CIGS (20\%) and then toward and beyond that of crystalline silicon (25\%)" (Snaith, H. J. Phys Chem. Lett. 4, 3623-3630 (2013).). Here, we investigate theoretically the crystalline phases of one of the hybrids relevant for photovoltaic applications, namely $\mathrm{CH}_{3} \mathrm{NH}_{3} \mathrm{PbCl}_{3}$. Critical electronic states and optical absorption are thoroughly investigated both in the low and high temperature phases. Our findings reveal the dramatic effect of spin orbit coupling on their multiple band gaps. Their physical properties are compared to those of conventional semiconductors, evidencing inversion of band edge states.
\end{abstract}

Keywords: Photovoltaic, Hybrid perovskite, density functional theory, semiconductor, optical absorption, spin-orbit coupling, solar cell

\section{INTRODUCTION}

In less than 20 years, the low-cost technologies and the ease synthesis of the Hybrid Organic Perovskites (HOP) raised up the interest in the field of optoelectronics [1,2] and solar cells [3-6]. The lead-halide based materials are currently the most investigated. They have the general formulae (R-NH3) ${ }_{\mathrm{n}} \mathrm{PbX}$, where $\mathrm{R}$ is an organic group and $\mathrm{X}$ a halogen atom. Control of the stoichiometry $(\mathrm{n}, \mathrm{m})$ affords crystal packing of various dimensionalities, ranging from three-dimensional (3D) corner-shared perovskite lattices (figure 1, [7]) to 0D structures with isolated inorganic octahedra.

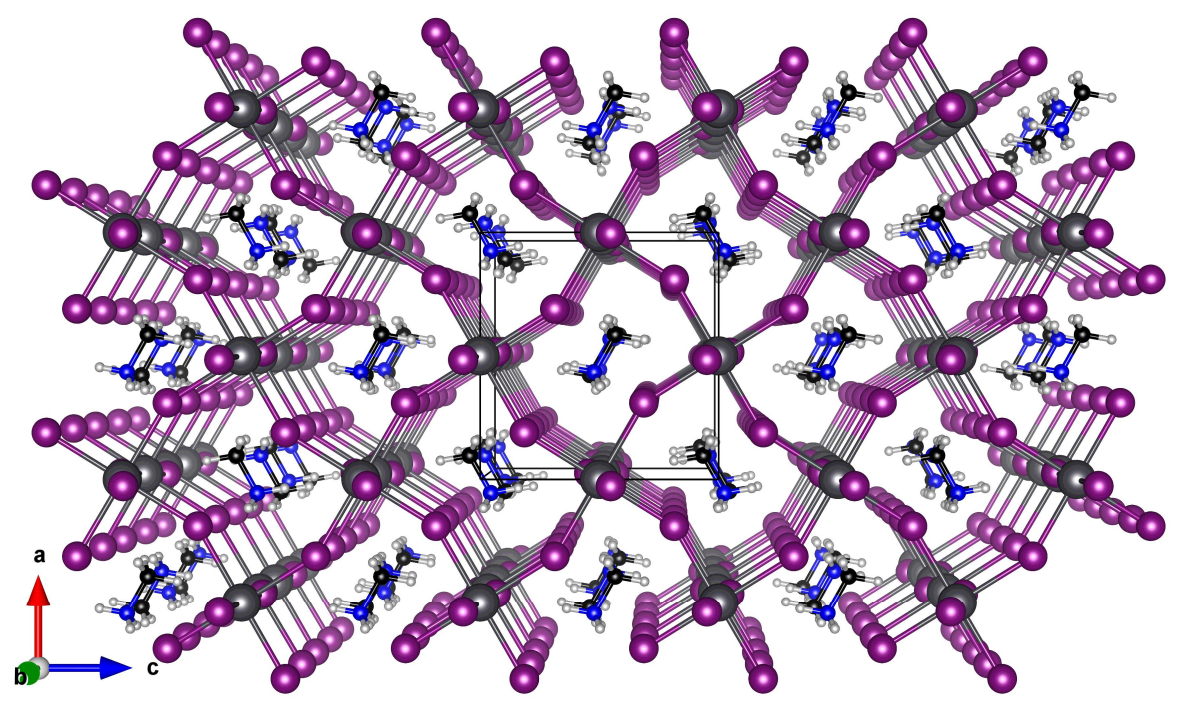

Figure 1. Perspective of the crystal structure of $\mathrm{CH}_{3} \mathrm{NH}_{3} \mathrm{PbI}_{3}$ at low temperature. The structure is orthorhombic (space group Pnma, [7]).

*jacky.even@insa-rennes.fr

Photonics for Solar Energy Systems V, edited by Ralf B. Wehrspohn, Andreas Gombert, Proc. of SPIE Vol. 9140, 91400Y · (c) 2014 SPIE

CCC code: $0277-786 X / 14 / \$ 18 \cdot$ doi: $10.1117 / 12.2052375$ 
The quantum and dielectric confinement expected in the 2D layered HOPs $(n=2, m=4)$ prompt active research to develop optoelectronic devices with enhanced performances [1,2]. Indeed, such layered structures have been demonstrated to show enhanced non-linear optical properties in microcavities [8]. More recently in 2012, 3D HOPs $(\mathrm{n}=1, \mathrm{~m}=3)$, with relatively small organic cations, have been suggested as a novel class of solution-processable low-cost materials for high efficient hybrid photovoltaic cells [3-6, 9-14]. Tremendous progress has been made in a short period of time, leading to both meso-superstructured solar cells and solid thin-film planar heterojunctions with record solar-toelectrical power conversion efficiencies. Most of the research effort has concentrate on methylammonium lead-iodide perovskites, $\left(\mathrm{CH}_{3} \mathrm{NH}_{3}\right)^{+}\left(\mathrm{PbI}_{3}\right)^{-}$, and chlorine-based mixed halides, $\left(\mathrm{CH}_{3} \mathrm{NH}_{3}\right)^{+}\left(\mathrm{PbI}_{3-\mathrm{x}} \mathrm{Cl}_{\mathrm{x}}\right)^{-}$. Recent experimental and theoretical work shows that better understanding could benefit from tools and concepts developed both in the fields of organic optoelectronics and conventional semiconductors. This can be envisioned as a change of paradigm sketched in Figure 2. Indeed, since the initial use of 3D HOP as the sensitizer in conventional dye sensitized solar cells (DSSC) by Miyasaka and collaborators [3], and the intermediate step by Park and colleagues [4], developments mainly driven by the groups at EPFL (Grätzel) [9-11] and Oxford (Snaith) [12-14] lead to a gradual shift of fundamental issues from materials chemistry to solid state physics. The multifaceted aspects of the change of paradigm related to the recent technological improvements made in the use of metal-halide perovskites for converting sunlight into electrical energy are illustrated Figure 2, including the pioneering work by Mitzi and collaborators on 2D HOP [1,2]. Further improvements will make the best profits from both fields.

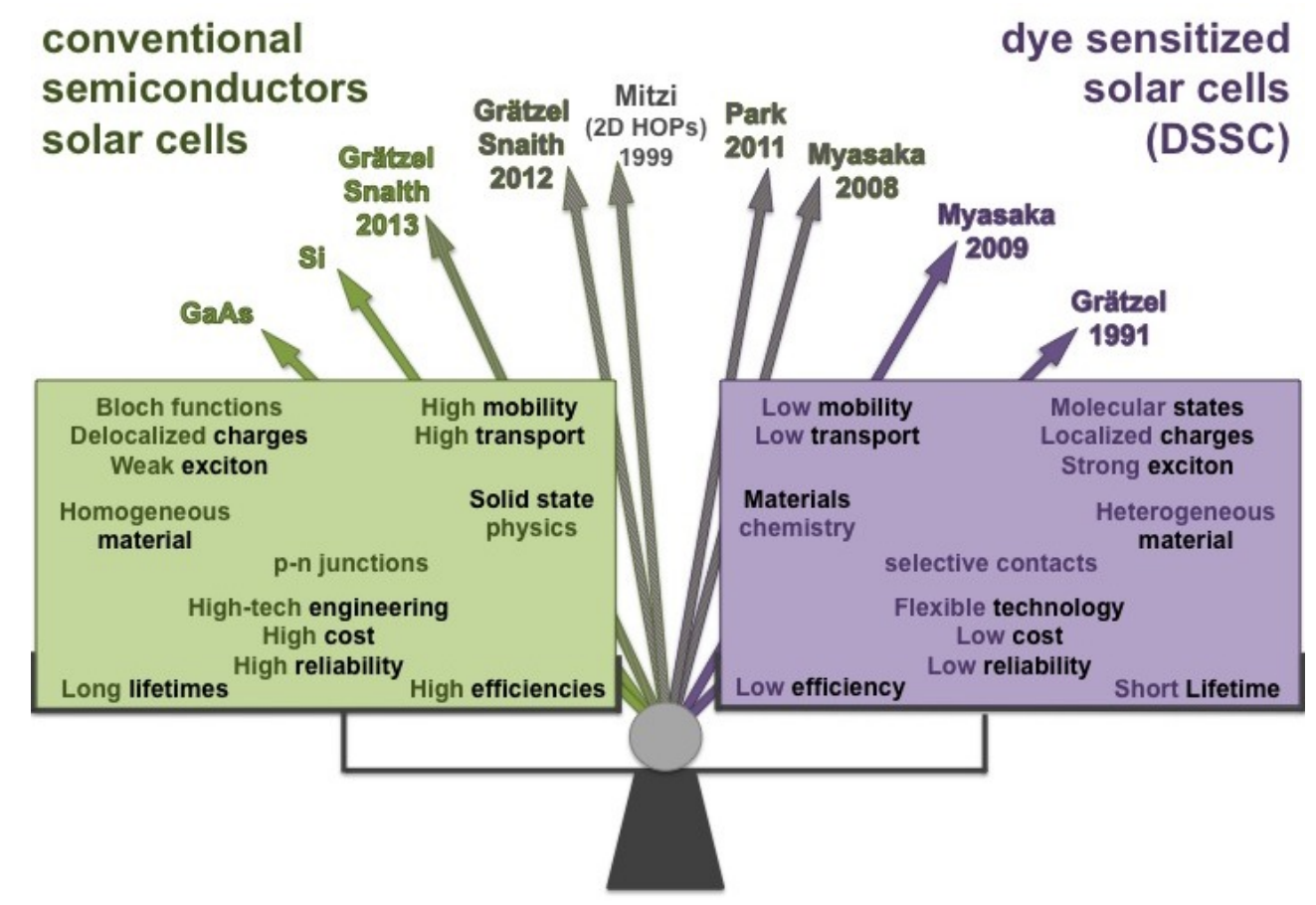

Figure 2. Multifaceted aspects of the recent change of paradigm driven by the groups at EPFL (Grätzel) [9-11] and Oxford (Snaith) [12-14], since the initial use of 3D HOP in DSSC by the group of Miyasaka [3] and the interim stage by Park and colleagues [4]. Mitzi's pioneering work on thin-film field effect transistors made of 2D HOPs [2] is also reported.

Thus, investigation of the physical properties of operational HOPs as well as the design of novel devices with enhanced optical responses may greatly benefit from the modeling of their optoelectronic properties. In this regard, Density Functional Theory (DFT) based simulations have proved their effectiveness. However, despite several recent DFT investigations performed for such 3D perovskites [15-23], there is still need for further insight. In fact, converting sunlight into electrical energy depends on several factors among which a broad absorption across the solar spectrum is of primary importance. 3D HOPs meet these prerequisite but, despite available theoretical work and foremost experimental research efforts in the last months [11,14], the understanding of their attractive light-harvesting abilities remains scarce. After a brief summary of related work, we herein investigate theoretically the lead-chloride hybrid perovskite $\mathrm{CH}_{3} \mathrm{NH}_{3} \mathrm{PbCl}_{3}$ that has not yet received much attention as compared to its lead-iodide counterpart. The choice for this 
compound is motivated by the improved transport properties and cell stability demonstrated for the mixed lead-halide $\mathrm{CH}_{3} \mathrm{NH}_{3} \mathrm{PbI}_{3-\mathrm{x}} \mathrm{Cl}_{\mathrm{x}}[13,14]$. Low and room temperature crystallographic phases are both be investigated and compared. Effect of spin-orbit coupling (SOC) is emphasized as it is still not systematically accounted for in current DFT computations, despite the large relativistic effects expected for lead-based compounds that have already been evidenced both in 2D [15] and 3D [18] HOPs.

\section{FIRST PRINCIPLE STUDY OF $\mathrm{CH}_{3} \mathrm{NH}_{3} \mathrm{PBCL}_{3}$}

\subsection{Computational Methods}

Calculations were performed using the DFT implementation available in the ABINIT package [24] with the LDA or the GGA-PBE gradient correction for exchange-correlation [25] and relativistic, norm-conserving, separable, dual-space Gaussian-type pseudopotentials of Goedecker, Teter, and Hutter for all atoms [26]. For Pb, we have verified that the band structures near the band-gap do not depend on the inclusion of 5d-orbitals $[17,18]$. The electronic wave-functions were expanded onto a plane-wave basis set with an energy cut-off of $950 \mathrm{eV} .4 \times 4 \times 4$ and 8x8x8 Monkhorst-Pack grids are used for reciprocal space integration in low temperature and high temperature structures, respectively. Calculations were performed with and without spin-orbit coupling (SOC). For simulating the high temperature phases, organic cations have been replaced by $\mathrm{Cs}^{+}$located at the nitrogen position. This procedure has already been checked previously for $\mathrm{CH}_{3} \mathrm{NH}_{3} \mathrm{PbI}_{3}$ and $\mathrm{CH}_{3} \mathrm{NH}_{3} \mathrm{PbBr}_{3}$ [18] and was further confirmed in this work using the low temperature structure of $\mathrm{CH}_{3} \mathrm{NH}_{3} \mathrm{PbCl}_{3}$ (see part 2.2).

\subsection{Results for $\mathrm{CH}_{3} \mathrm{NH}_{3} \mathrm{PbCl}_{3}$}

At low temperature, $\mathrm{CH}_{3} \mathrm{NH}_{3} \mathrm{PbI}_{3}$ (Figure 1, [7]) and $\mathrm{CH}_{3} \mathrm{NH}_{3} \mathrm{PbBr}_{3}$ [27] present an ordered orthorhombic structure of space-group Pnma $(Z=4)$, with a cell doubling when compared to the primitive cell of the room temperature partially disordered and centered tetragonal phase of $\mathrm{CH}_{3} \mathrm{NH}_{3} \mathrm{PbI}_{3}$ [28]. These ordered orthorhombic crystalline structures have already been used to perform a thorough DFT study of these HOPs [18]. Both compounds exhibit an averaged disordered cubic phase (space group $\mathrm{Pm} 3 \mathrm{~m}, \mathrm{Z}=1$ ) at high temperature [27]. The structural disorder is both associated to the rotation of methylammonium cations and tilts of lead-halide octaedra. The low temperature phase of $\mathrm{CH}_{3} \mathrm{NH}_{3} \mathrm{PbCl}_{3}$ was not yet investigated due to limitations of available computational resources. Indeed, this compound has also an orthorhombic low temperature phase (Pnma space group) (figure 3, [29]), but with a unit cell twice larger $(\mathrm{Z}=8)$ than that of $\mathrm{CH}_{3} \mathrm{NH}_{3} \mathrm{PbI}_{3}$ [7] and $\mathrm{CH}_{3} \mathrm{NH}_{3} \mathrm{PbBr}_{3}$ [27]. This is associated to a cell doubling in the (a,c) plane (figure 1).

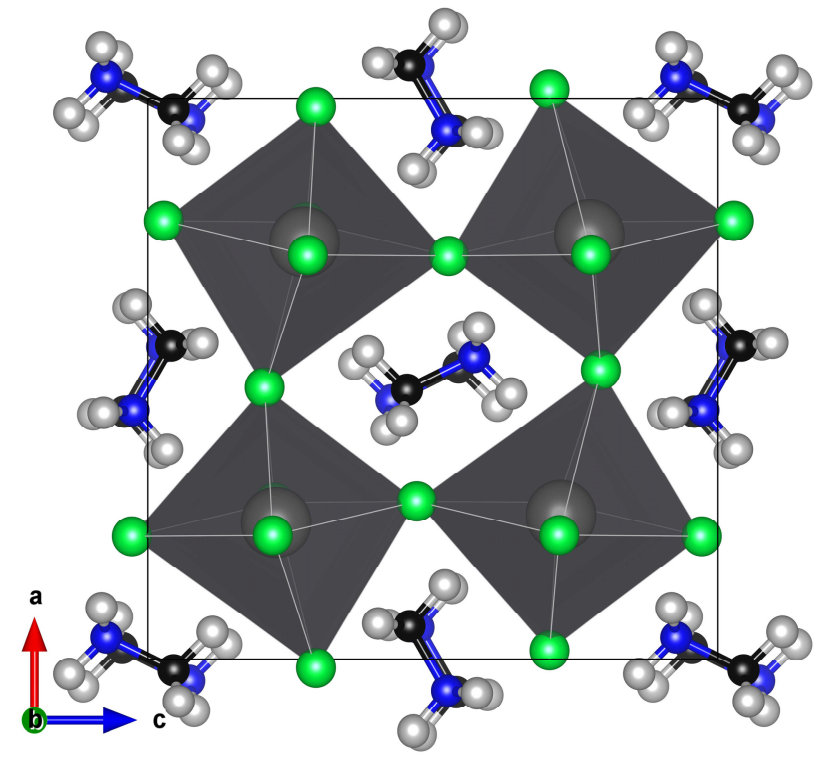

Figure 3. Overview of the crystal structure of $\mathrm{CH}_{3} \mathrm{NH}_{3} \mathrm{PbCl}_{3}$ at low temperature [29]. The structure is orthorhombic (space group Pnma, $\mathrm{Z}=8)$. The unit cell is twice larger than those reported for the low temperature phases $(\mathrm{Z}=4) \mathrm{of}_{\mathrm{CH}} \mathrm{NH}_{3} \mathrm{PbI}_{3}[7]$ and $\mathrm{CH}_{3} \mathrm{NH}_{3} \mathrm{PbBr}_{3}$ [27], and eight times larger than the disordered $\mathrm{Pm} 3 \mathrm{~m}$ cubic phase $(\mathrm{Z}=1)$ of $\mathrm{CH}_{3} \mathrm{NH}_{3} \mathrm{PbCl}_{3}$ at room temperature [28]. 


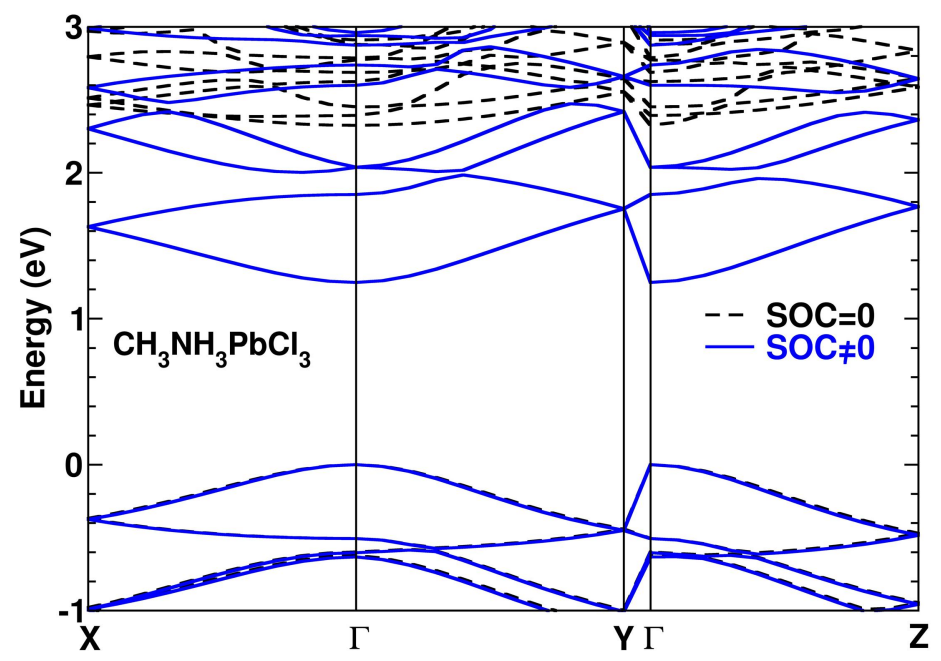

Figure 4. Electronic band diagrams for the low temperature orthorhombic Pnma phase of $\mathrm{CH}_{3} \mathrm{NH}_{3} \mathrm{PbCl}_{3}$ without (black dashed lines) and with (blue straight lines) SOC (LDA).

Figure 4 shows the electronic band diagrams for the low temperature orthorhombic Pnma phase of $\mathrm{CH}_{3} \mathrm{NH}_{3} \mathrm{PbCl}_{3}$ obtained with and without SOC. Consistently with earlier results on $\mathrm{CH}_{3} \mathrm{NH}_{3} \mathrm{PbI}_{3}$ and $\mathrm{CH}_{3} \mathrm{NH}_{3} \mathrm{PbBr}_{3}$ [18], the ground state transition reveals a direct band gap at the $\Gamma$-point. The direct nature of the band gap is an essential feature for physical properties such as absorption, photoconductivity and electroluminescence. Calculated band structures obtained without SOC (figure 1, black dashed lines) reveal different characteristics for the conduction band (CB) and the valence band (VB). Close to the band gap $(\Gamma)$, the VB consists primarily of one electronic band having almost isotropic energy dispersion. On the contrary, the $\mathrm{CB}$ evidences a more complex structure, with several different electronic states involved at the bottom of the CB. As shown in our previous studies on related compounds [18,21], we know from group theory that this stems from band folding in reciprocal space and symmetry breaking. In fact, symmetry analysis indicates that the $\mathrm{CB}$ electronic states at the $\Gamma$-point of the orthorhombic structure correspond to the triply degenerated states at the Rpoint (associated to the vectorial representation of the simple group [18,21]) of the room temperature Pm3m cubic phase. This apparent complex structure of the $\mathrm{CB}$ at low temperature is related to symmetry breaking that leads both to an increase of the unit cell volume and strain. It is worth emphasizing that the band diagram is analogous to the one of III-V bulk semiconductors in zinc-blende or würtzite structures, but with a reverse band edge electronic states ordering, including degenerate states in the CB instead of the VB.

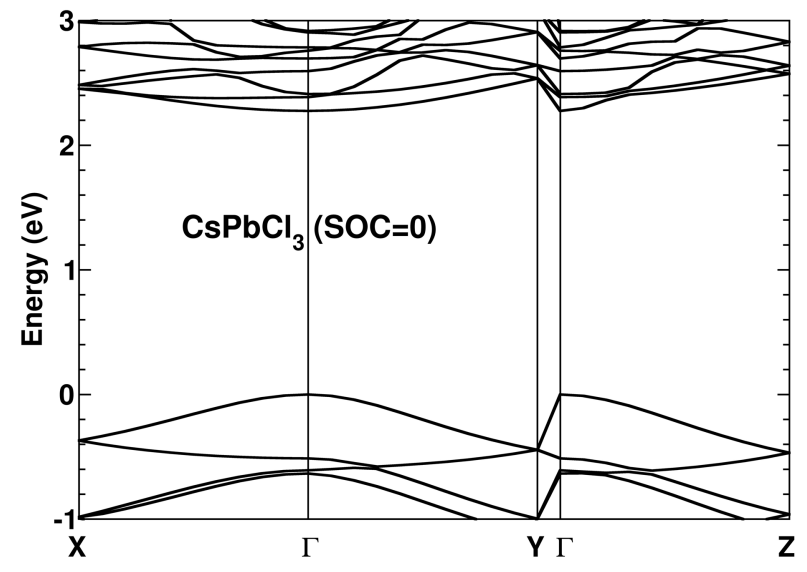

Figure 5. Electronic band diagrams for the approximate low temperature orthorhombic (Pnma) structure of $\mathrm{CH}_{3} \mathrm{NH}_{3} \mathrm{PbCl}_{3}$ obtained when replacing the $\mathrm{CH}_{3} \mathrm{NH}_{3}$ molecule by a $\mathrm{Cs}$ atom, located at the position of the $\mathrm{N}$ atom (LDA, without SOC). 
The important relativistic effects expected for lead have recently been evidenced both for 2D [15] and 3D [18] leadhalide based HOP, revealing giant SOC in the CB. Such dramatic effect of SOC is also visible in the calculated band structure of $\mathrm{CH}_{3} \mathrm{NH}_{3} \mathrm{PbCl}_{3}$ (figure 4, blue straight lines). This result confirms that SOC induces a larger effect than that introduced by strain, leading to a simplified electronic structure for the $\mathrm{CB}$. This is why effective mass approximations work well for both CB and VB of 2D [15] and 3D HOP [18,21]. Taking SOC into account is also important to properly describe absorption in 3D HOP. Indeed, the computed absorption at the band gap may be overestimated by a factor of three if SOC is neglected [18].

Before investigating the high temperature cubic phase of $\mathrm{CH}_{3} \mathrm{NH}_{3} \mathrm{PbCl}_{3}$, we need to briefly address a technical issue. In fact, in the cubic phase, methylammonium cations cannot be fixed in a preferential orientation without reducing the overall symmetry. The dynamical disorder of the organic cations thus hinders direct computation of the whole hybrid structure. Figure 5 reports the computed band structure of the orthorhombic low temperature structure of $\mathrm{CH}_{3} \mathrm{NH}_{3} \mathrm{PbCl}_{3}$ obtained when replacing each $\mathrm{CH}_{3} \mathrm{NH}_{3}$ with a cesium atom. The similarity between figure 5 and Figure 4 is striking and assesses further the validity of the substitution of the organic molecule by Cs, already checked for related lead-halide perovskites [18].

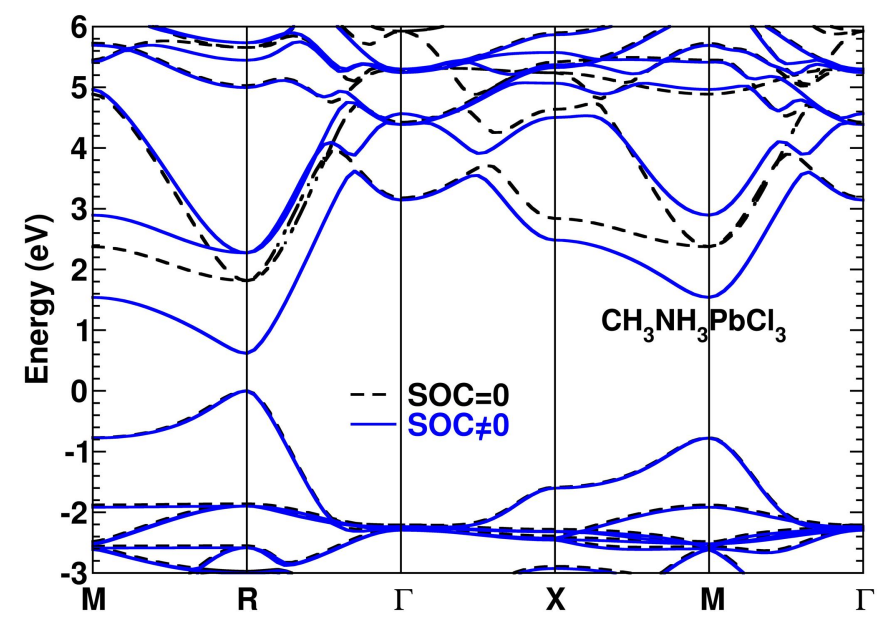

Figure 6. Electronic band diagrams for the approximate high temperature cubic ( $\mathrm{Pm} 3 \mathrm{~m})$ structure of $\mathrm{CH}_{3} \mathrm{NH}_{3} \mathrm{PbCl}_{3}$, obtained by substituting the methylammonium by a cesium atom without (black dashed lines) and with (blue straight lines) SOC (LDA).

Following this procedure, we compute the electronic band diagrams for the high temperature Pm $3 \mathrm{~m}$ cubic phase of $\mathrm{CH}_{3} \mathrm{NH}_{3} \mathrm{PbCl}_{3}$ both without (black dashed lines) and with (blue straight lines) SOC shown Figure 6. The ground state transition reveals a direct band gap at the R-point. Similarly to what has been observed for the low temperature phase (Figure 4), the giant SOC in the CB splits the triply degenerate electronic state at the conduction-band minimum. Figure 6 also evidences a secondary band gap at the M-point that is also influenced by SOC band splitting in the CB. A similar secondary band gap at the M-point has been reported for $\mathrm{CH}_{3} \mathrm{NH}_{3} \mathrm{PbI}_{3}$ and $\mathrm{CH}_{3} \mathrm{NH}_{3} \mathrm{PbBr}_{3}[18,21]$.

Regarding band gaps at R-point, we may notice that the value calculated without SOC $(1.8 \mathrm{eV})$ is closer to the experimental value $(3.1 \mathrm{eV},[30])$ than the value calculated with $\mathrm{SOC}(0.6 \mathrm{eV})$. An even better agreement has been obtained for $\mathrm{CH}_{3} \mathrm{NH}_{3} \mathrm{PbI}_{3}$ [18], but it is important to underline that this agreement is fortuitous and stems from large error cancellations. In fact, the band gap is known to be underestimated in DFT ground-state computations. This can be cured by including many-body effects as illustrated by the one-shot GW correction computed for the cubic phase of $\mathrm{CsPbI} 3$ amounting to a $0.6 \mathrm{eV}$ increase with respect to the LDA band gap [18]. Although not self-consistent, it indicates that GW and SOC impact band gaps in opposite directions. An accurate treatment would not only require self-consistent 
GW corrections and concomitant inclusion of SOC, but also the dynamical screening related to the motion of the organic cations. This is clearly out of reach with current DFT codes and computational power.

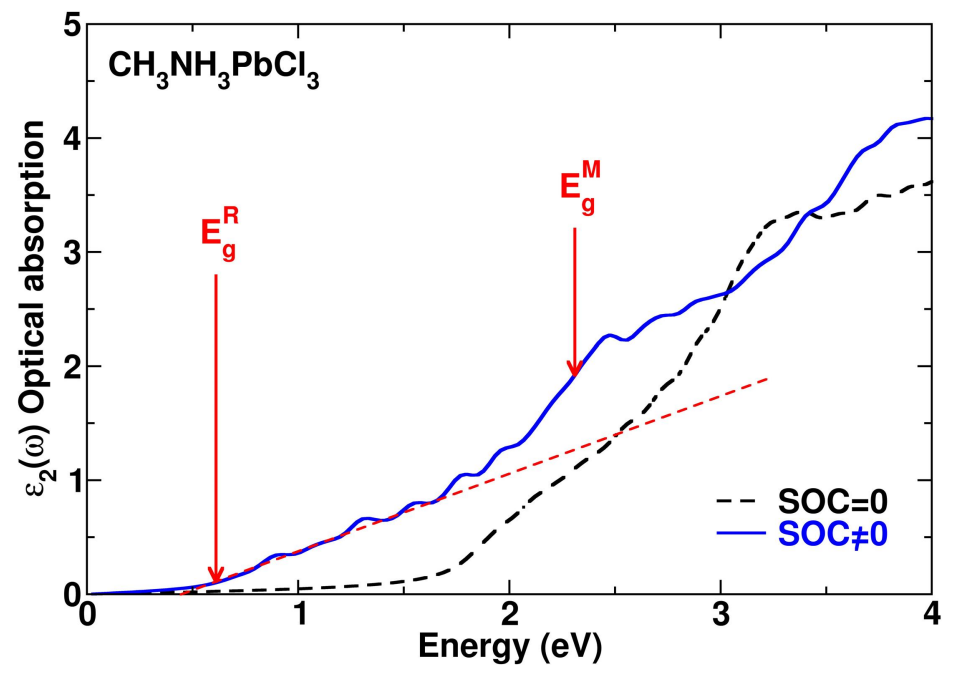

Figure 7. Optical absorption spectra of the approximate high temperature cubic $(\mathrm{Pm} 3 \mathrm{~m})$ phase of $\mathrm{CH}_{3} \mathrm{NH}_{3} \mathrm{PbCl}_{3}$ computed without (black dashed line) and with (blue straight line) SOC. Onsets of optical absorption at R and $\mathrm{M}$ are also indicated.

Band to band transitions allow computing the optical absorption spectrum of $\mathrm{CH}_{3} \mathrm{NH}_{3} \mathrm{PbCl}_{3}$ shown Figure 7. These results illustrate the shift of the optical band gap related to spin-orbit effects. Moreover, the slope of optical absorption near the band gap is smaller with SOC. This is related to the reduced number of critical states in the CB when SOC is considered (figures 4 and 6). The main band gap is located at the R-point but the secondary band gap at the M-point leads to further contributions to the optical absorption of $\mathrm{CH}_{3} \mathrm{NH}_{3} \mathrm{PbCl}_{3}$. A similar behavior has been reported for $\mathrm{CH}_{3} \mathrm{NH}_{3} \mathrm{PbI}_{3}$ and $\mathrm{CH}_{3} \mathrm{NH}_{3} \mathrm{PbBr}_{3}[18,21]$, demonstrating that it does not depend on the nature of the halogen atom. This allows hybrid perovskites to offer broad absorption across the solar spectrum, thus meeting one of the important prerequisites for efficient solar-to-electrical power conversion.

\section{CONCLUSION}

Tremendous progress has been made recently toward high efficient solar cells and optoelectronic devices using hybrid perovskites materials. Recent experimental studies showed that the mixed halide $\mathrm{CH}_{3} \mathrm{NH}_{3} \mathrm{PbI}_{3-\mathrm{x}} \mathrm{Cl}_{\mathrm{x}}[13,14]$ offers improved transport properties and cell stability. In line with our earlier work on $\mathrm{CH}_{3} \mathrm{NH}_{3} \mathrm{PbI}_{3}$ and $\mathrm{CH}_{3} \mathrm{NH}_{3} \mathrm{PbBr}_{3}[18,21]$, we have theoretically investigated both the low and high temperature phases of $\mathrm{CH}_{3} \mathrm{NH}_{3} \mathrm{PbCl}_{3}$. This affords systematic and thorough investigation of all reference non-mixed hybrid materials. It leads to similar conclusions than for the $\mathrm{CH}_{3} \mathrm{NH}_{3} \mathrm{PbI}_{3}$ and $\mathrm{CH}_{3} \mathrm{NH}_{3} \mathrm{PbBr}_{3}$ compounds. All three compounds show similar features. First, their band gap is dominated by giant spin-orbit effect acting mainly on the conduction band. This also happens for related 2D hybrids [15]. It reveals the importance of spin-orbit coupling and the reversed ordering of band-edge states as compared to tetrahedrally bonded semiconductors, for this class of lead-based perovskites, independently of their dimensionality. At room temperature, their remarkable light-harvesting properties can be related to direct and isotropic optical transitions between a triply degenerated conduction-band and a single valence-band in a simple group representation. In addition to the primary band gap at the R-point of the Brillouin zone, the secondary band gap at the M-point contributes to afford absorption of sunlight across a broad region of the solar spectrum. 


\section{REFERENCES}

[1] Mitzi, D. B., Wang, S., Field, C. A., Chess, C. A. and Guloy, A. M., "Conducting Layered Organic-inorganic Halides Containing <110>-Oriented Perovskite Sheets," Science, 267, 1473-1476 (1995).

[2] Kagan, C. R., Mitzi, D. B. and Dimitrakopoulos, C. D., "Organic-inorganic hybrid materials as semiconducting channels in thin-film field-effect transistors," Science, 286, 945-947 (1999).

[3] Kojima, A., Teshima, K., Shirai, Y. and Miyasaka, T., "Organometal Halide Perovskites as Visible-Light Sensitizers for Photovoltaic Cells," J. Am. Chem. Soc. 131 (17), 6050-6051 (2009).

[4] Im, J. H., Lee, C. R., Lee, J. W., Park, S. W. and Park, N. G., "6.5\% Efficient Perovskite Quantum-DotSensitized Solar Cell." Nanoscale, 3(10), 4088-4093 (2011).

[5] Park, N. G., "Organometal perovskite light absorbers toward a 20\% efficiency low-cost solid-state mesoscopic solar cell,” J. Phys Chem. Lett. 4, 2423-2429 (2013).

[6] Snaith, H. J., "Perovskites: The emergence of a new era for low-cost, high-efficiency solar cells," J. Phys Chem. Lett. 4, 3623-3630 (2013).

[7] Baikie, T., Fang, Y., Kadro, J. M., Schreyer, M., Wei, F., Mhaisalkar, S. G., Graetzel, M. and White, T. J., "Synthesis and crystal chemistry of the hybrid perovskite $\mathrm{CH}_{3} \mathrm{NH}_{3} \mathrm{PbI}_{3}$ for solid-state sensitised solar cell applications," J. Mater. Chem. A. 1, 5628-5641 (2013).

[8] Wei, Y., Lauret, J.-S., Galmiche, L., Audebert, P. and Deleporte, E., "Strong exciton-photon coupling in microcavities containing new fluorophenethylamine based perovskite compounds," Optics Express 20, 1039910405, (2012).

[9] Kim, H. S., Lee, C. R., Im, J. H., Lee, K. B., Moehl, T., Marchioro, A., Moon, S. J., Humphry-Baker, R., Yum, J. H., Moser, J. E., Grätzel, M. and Park, N-G., "Lead Iodide Perovskite Sensitized All-Solid-State Submicron Thin Film Mesoscopic Solar Cell with Efficiency Exceeding 9\%," Sci. Rep. 2, 591-591-7 (2012).

[10] Burschka, J., Pellet, N., Moon, S. J., Humphry-Baker, R., Gao, P., Nazeeruddin, M.K. and Grätzel, M., "Sequential deposition as a route to high-performance perovskite-sensitized solar cells," Nature 499, 316-319 (2013).

[11] Xing, G., Mathews, N., Sun, S., Lim, S. S., Lam, Y. M., Grätzel, M., Mhaisalkar, S. and Sum, T. C., "Longrange balanced electron- and hole-transport lengths in organic-inorganic $\mathrm{CH}_{3} \mathrm{NH}_{3} \mathrm{PbI}_{3}$," Science 342, 344-347 (2013).

[12] Lee, M. M., Teuscher, J., Miyasaka, T., Murakami, T. N. and Snaith, H. J., "Efficient Hybrid Solar Cells Based on Meso-Superstructured Organometal Halide Perovskites," Science 338, 643-647 (2012).

[13] Liu, M., Johnston, M. B. and Snaith, H. J., "Efficient planar heterojunction perovskite solar cells by vapour deposition," Nature 501, 395-398 (2013).

[14] Stranks, S. D., Eperon, G. E., Grancini, G., Menelaou, C., Alcocer, M. J. P., Leijtens, T., Herz, L. M., Petrozza, A. and Snaith, H. J., "Electron-hole diffusion lengths exceeding 1 micrometer in an organometal trihalide perovskite absorber," Science 342, 341-344 (2013).

[15] Even, J., Pedesseau, L., Dupertuis, M.-A., Jancu, J.-M. and Katan, C., "Electronic model for self-assembled hybrid organic/perovskite semiconductors: Reverse band edge electronic states ordering and spin-orbit coupling," Phys. Rev. B. 86, 205301-1-205301-4 (2012).

[16] Mosconi, E., Amat, A., Nazeeruddin, Md. K., Grätzel, M., De Angelis, F., "First-principles modeling of mixed halide organometal perovskites for photovoltaic applications," J. Phys. Chem. C, 117, 13902-13913, (2013).

[17] Pedesseau, L., Jancu, J-M., Rolland, A., Deleporte, E., Katan, C. and Even, J., "Electronic properties of 2D and 3D hybrid organic/inorganic perovskites for optoelectronic and photovoltaic applications," Opt. Quant. Electron. doi: 10.1007/s11082-013-9823-9 (2013).

[18] Even, J., Pedesseau, L., Jancu, J.-M. and Katan, C., "Importance of spin-orbit coupling in hybrid organic/inorganic perovskites for photovoltaic applications," J. Phys. Chem. Lett. 4, 2999-3005 (2013).

[19] Brivio, F., Walker, A. B., Walsh, A, "Structural and electronic properties of hybrid perovskites for highefficiency thin-film photovoltaics from first-principles," Appl. Phys. Lett. Mat. 1, 042111-1-042111-5 (2013).

[20] Giorgi, V., Fujisawa, J.-I., Segawa, H., Yamashita, K., "Small photocarrier effective masses featuring ambipolar transport in methylammonium lead iodide perovskite: A density functional analysis," J. Phys. Chem. Lett. 4, 4213-4216 (2013).

[21] Even, J., Pedesseau, L., Jancu, J.-M. and Katan, C., "DFT and k • p modelling of the phase transitions of lead and tin halide perovskites for photovoltaic cells," Phys. Status Solidi RRL. 8, 31-35 (2014). 
[22] Yin, W-J., Shi, T., and Yan, Y., "Unusual defect physics in $\mathrm{CH}_{3} \mathrm{NH}_{3} \mathrm{PbI}_{3}$ perovskite solar cell absorber", Appl. Phys. Lett., 104, 063903-1-063903-4 (2014).

[23] Quarti, C., Grancini, G., Mosconi, E., Bruno, P., Ball, J. M., Lee, M. M., Snaith, H. J., Petrozza, A., De Angelis, F., "The Raman Spectrum of the $\mathrm{CH}_{3} \mathrm{NH}_{3} \mathrm{PbI}_{3}$ Hybrid Perovskite: Interplay of Theory and Experiment" J. Phys. Chem. Lett. 5, 279-284 (2014).

[24] Gonze, X., Amadon, B., Anglade, P. M., Beuken, J. M., Bottin, F., Boulanger, P., Bruneval, F., Caliste, D., Caracas, R., Cote, M. et al, "ABINIT: First-principles approach to material and nanosystem properties," Comp. Phys. Comm. 180 (12), 2582-2615 (2009).

[25] Perdew, J. P., Burke, K., Ernzerhof, M., “Generalized gradient approximation made simple.,” Phys. Rev. Lett. 77, 3865-3868 (1996).

[26] Hartwigsen, C., Goedecker, S. and Hutter, J., "Relativistic separable dual-space Gaussian pseudopotentials from H to Rn," Phys. Rev. B 58 (7), 3641-3662 (1998).

[27] Swainson, I. P., Hammond, R. P., Soulliere, C., Knop, O., Massa, W., "Phase transitions in the perovskite methylammonium lead bromide, $\mathrm{CH}_{3} \mathrm{ND}_{3} \mathrm{PbBr}_{3}$," J. Solid State Chem. 176, 97-104 (2003).

[28] Poglitsch, A. and Weber, D., "Dynamic disorder in methylammoniumtrihalogenoplumbates (II) observed by millimeter-wave spectroscopy," J. Chem. Phys. 87, 6373-6378 (1987).

[29] Chi, L., Swainson, I., Cranswicka, L., Herb, J-H, Stephens, P. and Knop, O., “The ordered phase of methylammonium lead chloride $\mathrm{CH}_{3} \mathrm{ND}_{3} \mathrm{PbCl}_{3}$," J. Solid State Chem. 178, 1376-1385 (2005).

[30] Kitazawa, N., Watanabe, Y., Nakamura, Y., "Optical properties of $\mathrm{CH}_{3} \mathrm{NH}_{3} \mathrm{PbX}_{3}(\mathrm{X}=$ halogen) and their mixed-halide crystals," J. Mat. Sci. 37, 3585-3587 (2002). 